\title{
Affective priming of emotional pictures in parafoveal vision: Left visual field advantage
}

\author{
Manuel G. Calvo and Pedro Avero \\ University of La Laguna, Tenerife, Spain
}

\begin{abstract}
This study investigated whether stimulus affective content can be extracted from visual scenes when these appear in parafoveal locations of the visual field and are foveally masked, and whether there is lateralization involved. Parafoveal prime pleasant or unpleasant scenes were presented for $150 \mathrm{msec} 2.5^{\circ}$ away from fixation and were followed by a foveal probe scene that was either congruent or incongruent in emotional valence with the prime. Participants responded whether the probe was emotionally positive or negative. Affective priming was demonstrated by shorter response latencies for congruent than for incongruent prime-probe pairs. This effect occurred when the prime was presented in the left visual field at a $300-$ msec prime-probe stimulus onset asynchrony, even when the prime and the probe were different in physical appearance and semantic category. This result reveals that the affective significance of emotional stimuli can be assessed early through covert attention mechanisms, in the absence of overt eye fixations on the stimuli, and suggests that right-hemisphere dominance is involved.
\end{abstract}

In models of emotional processing, researchers have proposed that the affective valence of stimuli (i.e., whether they are "good" or "bad") can be automatically assessed (i.e., quickly, efficiently, unintentionally, and/or unconsciously; see Bargh, 1997; Zajonc, 2000). The emotional content of appetitive and aversive stimuli is thought to be especially accessible to analysis by the cognitive system because of their adaptive importance: Automatic processing would be functional in recruiting metabolic, mental, and behavioral resources early and would therefore serve to prompt a rapid onset of preservative or protective responses in order to maximize benefit and minimize harm. Evidence for automatic emotional processing comes from studies in which pictorial stimuli are very briefly presented and masked (Banse, 2001, with an affective priming paradigm; Calvo \& Esteves, 2005, with recognition measures; Dimberg, Thunberg, \& Elmehed, 2000, with electromyographical assessment; Öhman \& Soares, 1998, with skin conductance responses). Furthermore, brain studies using event-related potential (ERP) measures have shown very short latencies of cortical activation and electrophysiological differentiation between neutral and fearful faces (Pourtois, Thut, Grave de Peralta, Michel, \& Vuilleumier, 2005), liked and disliked faces (Pizzagalli, Regard, \& Lehmann, 1999), unpleasant, pleasant, and neutral scenes (Keil et al., 2001), and even conditioned stimuli associated with aversive versus neutral pictures (Storalova, Keil, $\&$ Moratti, 2006), as early as between 70 and $120 \mathrm{msec}$ following stimulus onset.

These findings reveal that sensory processing is enhanced by emotional content (see Vuilleumier, 2005). An important question is to what extent attention is involved in this privileged affective assessment. Attention selects and keeps accessible stimulus and mental input for analysis by the cognitive system. To accomplish this function, visual attention uses an overt orienting mechanism, by means of saccades and eye fixations on a target stimulus, and a covert orienting mechanism, through internal neural adjustments without eye movements (see Posner \& Petersen, 1990; Wu \& Remington, 2003). Neurophysiological and neuropsychological findings show that there are overlapping and common brain areas activated by both saccades and covert shifts of attention (Corbetta, 1998; Ignashchenkova, Dicke, Haarmeier, \& Their, 2004). Although there is a strong natural relationship between these orienting mechanisms, with covert attention assisting in the preprocessing of information in the visual periphery at the location where the eyes are to be directed (Findlay \& Gilchrist, 2003), the two mechanisms can be dissociated (see Posner \& Petersen, 1990). An interesting issue is concerned with their differential involvement in affective processing.

The aim of the present study was to investigate, first, whether affective processing of emotional visual scenes can be accomplished by means of covert attention in the absence of overt attention to the stimuli and, second, whether the effectiveness of covert attention processes varies depending on the hemifield of stimulus presentation. Prior research on affective processing of emotional pictures has typically presented the stimuli at fixation, in the center of the visual field. Doing so means that the stimuli were available to overt attention; therefore, the differential contribution of overt and covert attention could not be determined. Furthermore, the central location of the stimuli implies that they were similarly available to both visual hemifields; therefore, potential lateralization effects could not be assessed. In the present study, we ex-

M. G. Calvo, mgcalvo@ull.es 
amined whether affective processing can be performed by covert attention, with no fixations on the stimuli. To this end, we presented emotional scenes at parafoveal, eccentric locations of the visual field, whereas overt attention was allocated elsewhere to an unrelated foveal stimulus, and there was gaze-contingent foveal masking of the scenes. These conditions were assumed to prevent overt attention to the pictures but would allow covert attention (see Calvo \& Nummenmaa, 2007). By presenting the parafoveal scenes to either the left or the right visual field, we addressed the additional issue of hemispheric lateralization and dominance in covert attention.

\section{Processing of Unattended Emotional Visual Scenes}

Two lines of prior research are particularly relevant to the aims of this study regarding the emotional processing of pictorial stimuli in the absence of overt attention. First, brain activation studies have not provided conclusive findings. On the one hand, Eimer, Holmes, and McGlone (2003) presented two faces bilaterally $2.2^{\circ}$ to the left and right of fixation. When participants had to direct their overt attention to the faces, enhanced early fronto-central positivity - as measured by ERPs - was elicited by emotional faces (anger, disgust, fear, happiness, sadness, and surprise) as opposed to neutral faces. In contrast, when overt attention had to be directed to two central lines, ignoring the lateral faces, the emotional expression effects disappeared. Such attentional modulation is further supported by fMRI evidence. Pessoa, McKenna, Gutierrez, and Ungerleider (2002) found amygdala responses to fearful or happy rather than neutral facial expressions only when sufficient attentional resources were available to process the faces, but not when attention was directed to irrelevant peripheral stimuli. On the other hand, activation of the amygdala and right fusiform gyrus has been reported — as assessed by fMRIfor fearful versus neutral faces presented approximately between $1.1^{\circ}$ and $1.4^{\circ}$ away from a central fixation point (Vuilleumier, Armony, Driver, \& Dolan, 2001). A similar conclusion supporting the processing of emotional stimuli outside the focus of overt attention was reached by Keil, Moratti, Sabatinelli, Bradley, and Lang (2005) with an ERP measure. These authors found enhanced activation in the occipito-temporal and parietal cortex for highly arousing scenes, in comparison with neutral scenes, when the stimuli appeared $1.3^{\circ}$ away from the center of fixation.

A second source of evidence for parafoveal processing of emotional content comes from eye movement research. When pairs of emotional and neutral scenes were presented simultaneously $2.5^{\circ}$ (or more) away from a central fixation point, the next first fixation of the eyes was especially likely to be placed on the emotional scene (Calvo \& Lang, 2004, 2005; Nummenmaa, Hyönä, \& Calvo, 2006). This result reveals initial orienting to the emotional stimuli. If we assume that shifts of covert visual attention precede eye movements to a location in space (see Findlay \& Gilchrist, 2003), then the fact that first fixation was more likely to be directed to the emotional scene of the pair implies that this scene, rather than the neutral one, was attended to covertly (i.e., parafoveally) prior to the eye movement. Since this occurred when differences in low-level perceptual features (luminance, contrast, and color saturation) between the emotional and the neutral stimuli were controlled, we may infer that the meaning of the emotional scenes was responsible for such an early orienting effect - that is, "something" of their meaningful content was processed parafoveally, which then drew overt attention. The question is, precisely what kind of meaning was processed prior to the selective saccades toward the emotional pictures? The hypothesis to be investigated in the present study is, in fact, that the affective significance of the emotional stimuli is assessed while the emotional scenes are outside foveal vision, and that it was this affective content that then attracted the eyes preferentially to the emotional stimuli in the Calvo and Lang $(2004,2005)$ and the Nummenmaa et al. studies.

\section{Laterality: Visual Field and Hemisphere Dominance}

A specific issue in this approach to the processing of unattended emotional stimuli involves lateralization - that is, whether affective processing varies as a function of whether the stimulus is presented to the right or the left of fixation. Knowing this will allow us to infer whether there is brain hemisphere dominance in the assessment of emotional content. Essentially, there are two models of emotion perception regarding lateralization (see Borod, Zgaljardic, Tabert, \& Koff, 2001; Murphy, Nimmo-Smith, \& Lawrence, 2003; Rodway, Wright, \& Hardie, 2003). According to righthemisphere models, there is a right-hemisphere dominance (hence, left visual field advantage) in the perception and interpretation of emotional expressions. According to valencespecific laterality models, hemispheric biases depend on the emotional valence of the stimulus, with a left-hemisphere dominance for the perception of positive emotions and righthemisphere dominance for the perception of negative emotions. In a review of the literature (Borod et al., 2001), of the 20 studies reviewed, 17 produced results consistent with the right-hemisphere hypothesis, 2 showed no laterality effects, and only 1 produced results that were consistent with the valence specificity hypothesis. Nevertheless, the majority of studies dealing with this issue have used facial expressions as stimuli. In a meta-analysis study, Murphy et al. (2003) failed to support a special role of the right hemisphere in emotion perception when a wider range of stimulus modalities was considered (visual, auditory, olfactory, tactile, and taste).

It is, however, possible that laterality varies for different types of stimuli. Particularly, visual scenes depicting people's emotional expressions and actions are assumed to have a special status as affective stimuli, in comparison with isolated faces: Emotional faces in an action context (e.g., someone kissing a smiling face, in comparison with a single smiling face; or an angry person who is aiming a gun at the observer, in comparison with an angry face alone) would enhance emotional intensity and informativeness of the stimulus. Such enhancement would make the scenes particularly salient, since emotional stimuli and particular brain structures might be more sensitive to them than to isolated faces. Keil et al. (2005) found support for the right-hemisphere dominance hypothesis 
in the processing of emotional scenes. ERPs were recorded for pictures that were presented to either the left or the right of a concurrent distractor at fixation. Right occipito-temporal and parietal activation was found when an unpleasant scene (in comparison with a neutral scene) was presented in the left visual field. This result suggests that emotional information has facilitated access to righthemisphere sites in the brain. Nevertheless, the pictures in Keil et al.'s (2005) study were located only $1.3^{\circ}$ away from the central fixation point, which still probably allowed for some foveal vision of them (see Wandell, 1995, for a description of the human retina). A more stringent test of this hypothesis would involve presenting the stimuli at more eccentric locations. With this aim in mind, in the present study, the eccentricity was increased to $2.5^{\circ}$.

\section{The Present Study: Assessment of Affective Priming of Parafoveal Emotional Pictures}

The affective priming paradigm has been used to investigate the processing of stimulus affective valence (see Klauer \& Musch, 2003). In a typical study, an emotionally positive or negative prime (e.g., a word or a picture) is followed by a probe. Participants decide whether the probe stimulus is positive or negative in emotional valence. Findings have shown an affective priming effect: Responses to the probe are faster when it is preceded by a congruent (i.e., same valence) prime than when it is preceded by an incongruent (i.e., different valence) prime. A number of studies have used pictures as both primes and probes (Avero \& Calvo, 2006; Carroll \& Young, 2005; Hermans, De Houwer, \& Eelen, 1994; Hermans, Spruyt, De Houwer, \& Eelen, 2003; Hietanen \& Korpela, 2004; Spruyt, Hermans, De Houwer, \& Eelen, 2002; Storbeck \& Robinson, 2004). In most of these studies, with the notable exception of Storbeck and Robinson, an affective priming effect was found at short stimulus onset asynchronies (SOAs) between the prime and the probe. This result has led researchers to conclude that the affective significance of the prime is assessed very early.

Nevertheless, in all the affective priming studies, emotional pictures were presented foveally (i.e., in the center of the visual field). We have adapted this paradigm to address the question of whether affective information is obtained also outside the focus of overt attention, and whether there are lateralization effects. The methodological approach involved presenting one parafoveal picture as a prime, followed by another as a foveal probe. The prime appeared with its inner edge $2.5^{\circ}$ away from the center of a foveal letter at fixation that the participant had to identify and name. Both the prime picture and the letter appeared simultaneously for $150 \mathrm{msec}$. We assumed that (and tested whether) doing so would prevent eye movements to the parafoveal picture. Following an interval of either 150 or $650 \mathrm{msec}$ (hence, SOAs of 300 or $800 \mathrm{msec}$ ), the probe picture appeared, and the participant responded whether it was positive or negative in an evaluative decision task. The prime and the probe belonged to either the same or a different category (people vs. animals). The parafoveal prime was either preexposed foveally or not. Affective priming was determined by whether the reac- tion times (RTs) to the probe were shorter when it was congruent in affective valence (i.e., pleasant-pleasant, or unpleasant-unpleasant) with the prime than when it was preceded by an incongruent prime (i.e., unpleasantpleasant, or pleasant-unpleasant).

This approach allowed us to examine the following predictions. First, if there is processing of the affective meaning of the prime stimulus, then priming will occur whenever there is affective prime-probe congruence, regardless of whether the stimuli differ in physical appearance and semantic category. Second, if the affective significance is assessed early, then priming will appear at a $300-\mathrm{msec}$ $\mathrm{SOA}$, and whether it is short or long lived will be indicated by the strength of priming at an $800-\mathrm{msec}$ SOA. Third, if the analysis of affective content overrides detailed perceptual processing, then affective priming will emerge the first time the prime stimulus is presented parafoveally, without any recent foveal experience of the stimulus. Fourth, if right-hemispheric neural structures are especially sensitive to unattended affective content, then priming will be more likely to occur when the stimuli are presented in the left visual field than when presented in the right field. And, finally, these priming effects will occur in the absence of eye fixations on the parafoveal prime stimulus.

\section{EXPERIMENT 1}

Prime unpleasant or pleasant pictures were presented for $150 \mathrm{msec}, 2.5^{\circ}$ away from a central fixation letter, followed by a probe that was congruent or incongruent in emotional valence, at short $(300 \mathrm{msec})$ or long $(800 \mathrm{msec})$ SOAs. These prime-probe pairs were presented only once to avoid preexposure or practice effects.

\section{Method}

Participants. Forty-eight psychology undergraduates (38 females, 10 males) at La Laguna University participated for course credit. Participants were different for all the experiments (although they were drawn from the same pool of students during the second term and were assigned to each experiment randomly) in order to allow for comparisons across the experiments. The participants in all the experiments were from 19 to 24 years of age $(M=21.3)$. The proportion of right-handed participants was equivalent in all of the experiments (between $83.4 \%$ and $91.7 \%$ ). Half of the participants of each gender group were randomly assigned to each SOA condition.

Stimuli and Apparatus. Sixty pictures describing unpleasant (30 pictures) or pleasant (30 pictures) scenes involving people were selected from the International Affective Picture System (IAPS; Center for the Study of Emotion and Attention, 1999). The IAPS numbers are indicated in the Appendix. The mean IAPS valence scores of the selected pictures in undergraduate Spanish samples were 2.30 (unpleasant) and 7.73 (pleasant) in a 9-point scale $[t(58)=36.56$, $p<.0001]$. The respective rated arousal scores were 6.99 and 4.99 $[t(58)=6.63, p<.0001]$.

Both as a prime and as a probe, each picture subtended a visual angle of $13.3^{\circ}$ (width; $\left.11.7 \mathrm{~cm}\right) \times 11.1^{\circ}$ (height; $9.7 \mathrm{~cm}$ ), at a constant viewing distance of $50 \mathrm{~cm}$. The distance from the center of the letter that served as the fixation point to the inner edge of the prime picture was $2.5^{\circ}(2.2 \mathrm{~cm})$, so that the prime stimulus was located in parafoveal vision. The central letter subtended an angle of $0.8^{\circ} \times 1^{\circ}$. Participants had their heads positioned in a chin and forehead rest. All pictures were presented in their original colors against a dark background. The pictures were displayed on an SVGA 17-in. monitor with a $100-\mathrm{Hz}$ refresh rate, at a resolution of $800 \times 600$ 
pixels, connected to a Pentium IV computer. The E-Prime experimental software (Schneider, Eschman, \& Zuccolotto, 2002) controlled stimulus presentation and response collection. Response accuracy and latency on the probe evaluation task were collected through keypresses. For half of the participants, the "positive" response key was "D," and the "negative" key was "L" on a standard computer keyboard, whereas the reverse applied to the other half of the participants.

Procedure and Design. The participants were informed that they would be presented with a sequence of two photographs on each trial: The first photograph (the prime) could appear to either the left or the right of a central fixation point (a letter), and the second (the probe) would always appear in the center of the screen. They were also told that the letter (A or $\mathrm{O}$ ) serving as the central fixation point would appear at the same time as the prime. The participants' task was twofold: First, the letter should be named aloud as soon as it appeared, with accuracy being recorded through a microphone; second, when the probe appeared, the participants should promptly respond - by pressing a key — whether it was pleasant or unpleasant. Participants were asked to ignore the prime and pay attention to the concurrent letter. Figure 1 shows the sequence of events on each trial (with the exception that there was no preview phase in Experiment 1). A trial started with a central cross for $500 \mathrm{msec}$, followed by the prime stimulus (left or right) and the to-be-named letter (A or O) for $150 \mathrm{msec}$, a blank 150 - or 650 -msec interval, and finally the probe stimulus, which remained on the screen until the participants responded, or for $2 \mathrm{sec}$. The intertrial interval was $2 \mathrm{sec}$. Following 16 practice trials, each participant was presented with 60 experimental trials.

The experimental conditions were combined in a mixed factorial design in which SOA (300 vs. $800 \mathrm{msec})$ was a between-subjects factor, with 24 participants at each level, and emotional valence of the probe (unpleasant vs. pleasant), prime-probe congruence (congruent vs. incongruent), and visual field of the prime (left vs. right) were within-subjects factors. Each picture was presented once as a prime and once as a probe, with random assignment of primes and probes and random trial order.

\section{Results and Discussion}

There was nearly total performance accuracy in the letter identification task, with less than $1 \%$ of errors across all four experiments, and no differences as a function of experimental conditions. RTs on this task were not recorded. Regarding performance on the affective evaluation of the probe, accuracy ( $4.2 \%$ total errors and misses) did not differ across experiments or conditions. Subsequent analyses were conducted on RTs for correct responses. To deal with outliers, we excluded from the analyses RTs above $1,500 \mathrm{msec}$ or below $300 \mathrm{msec}(1.9 \%$, across experiments). RTs that were $2.5 \mathrm{SDs}$ above or below the mean in each experimental condition were replaced by the $\pm 2.5 S D$ values ( $2.9 \%$ of cases across experiments).

For RTs on correct responses in Experiment 1, the 2 $(\mathrm{SOA}) \times 2$ (valence of probe) $\times 2$ (prime-probe congruence) $\times 2$ (visual field of prime) ANOVA yielded only a significant effect of SOA $[F(1,46)=4.25, p<.05]$, with shorter RTs at $800-\mathrm{msec}(763 \mathrm{msec})$ than at $300-\mathrm{msec}$ SOA ( $848 \mathrm{msec})$. Response latencies tended to be shorter for congruent than for incongruent probes at $300-\mathrm{msec}$ SOA ( 837 vs. $858 \mathrm{msec}$, respectively), especially following left-hemifield primes (see Table 1), in comparison with 800 -msec SOA (766 vs. $761 \mathrm{msec}$, respectively). Nevertheless, the congruence $\times$ SOA interaction did not reach statistical significance $[F(1,46)=2.39, p=.12$, n.s.], nor did the congruence $\times \mathrm{SOA} \times$ visual field interaction $[F(1,46)=$ $1.85, p=.18, \mathrm{n} . \mathrm{s}$.]. The mean scores are shown in Table 1 . An affective priming index was computed by subtracting RTs for probes following a congruent prime from those following an incongruent prime (difference $\mathrm{I}-\mathrm{C}$ ), where positive scores indicate facilitation for the congruent probe and negative scores indicate interference.

There was only a nonsignificant tendency of affective priming at the shorter $(300-\mathrm{msec})$ SOA. This is in contrast with the clear priming effects found by Avero and Calvo (2006) when the same prime-probe pictures were presented foveally, and using the same temporal parameters as those in the present study. A tentative conclusion is that affective significance is assessed through overt attention (Avero \& Calvo, 2006), but not through covert attention (present study). However, this conclusion would be at odds with prior research that has found either facilitated orienting to emotional pictures (as shown by eye movements; Calvo \& Lang, 2004; Nummenmaa et al., 2006) or

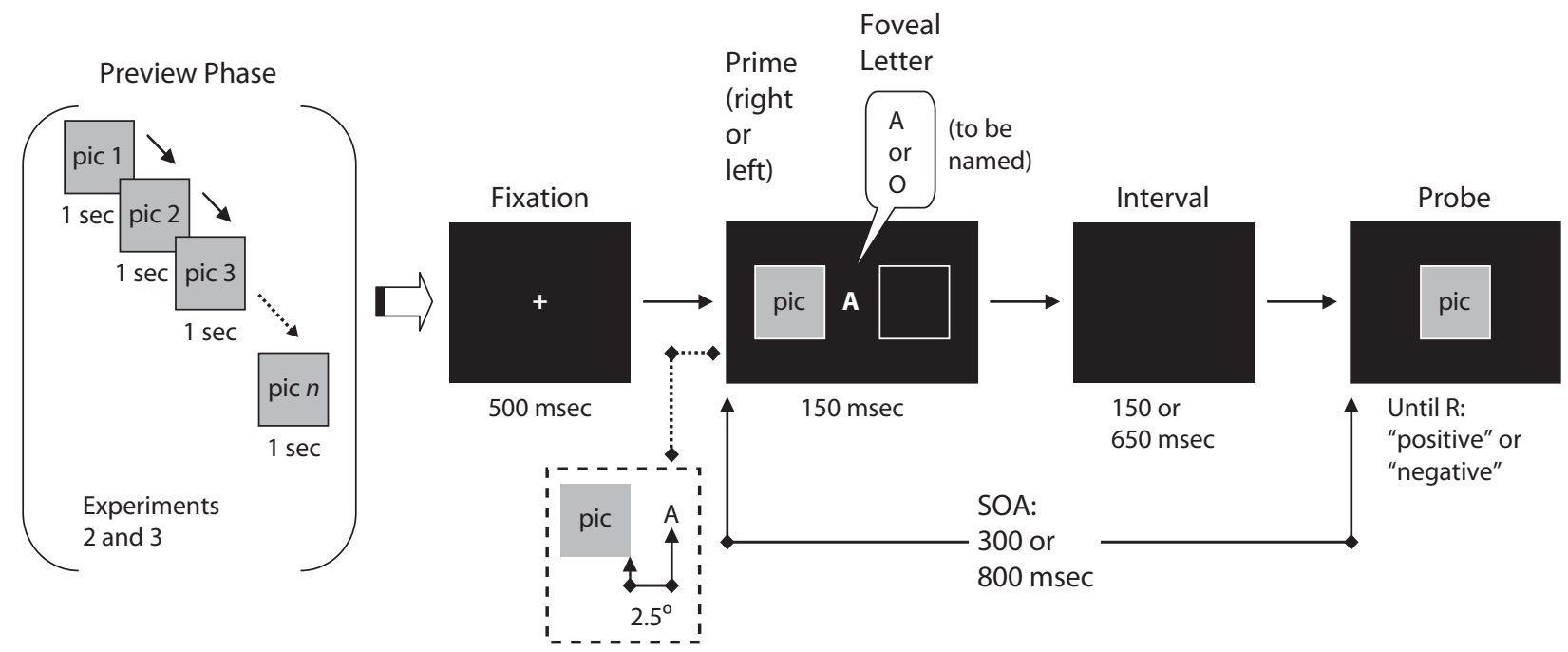

Figure 1. Sequence of events within a trial in Experiments 1-3 (preview phase only in Experiments 2 and 3 ). 
Table 1

Mean Reaction Times (in Milliseconds) for Correct Affective Evaluation Responses in

Experiment 1, and Difference Scores (Incongruent - Congruent Conditions) for Each Visual Field (LVF, RVF) and Stimulus Onset Asynchrony (SOA)

\begin{tabular}{|c|c|c|c|c|c|c|c|c|c|c|}
\hline \multirow[b]{4}{*}{ SOA } & \multicolumn{8}{|c|}{ Prime-Probe Relatedness } & \multirow{3}{*}{\multicolumn{2}{|c|}{$\begin{array}{c}\text { Affective } \\
\text { Priming } \\
\text { (Differ. I - C }\end{array}$}} \\
\hline & \multicolumn{4}{|c|}{ Congruent (C) } & \multicolumn{4}{|c|}{ Incongruent (I) } & & \\
\hline & \multicolumn{2}{|c|}{ LVF } & \multicolumn{2}{|c|}{ RVF } & \multicolumn{2}{|c|}{ LVF } & \multicolumn{2}{|c|}{ RVF } & & \\
\hline & $M$ & $S D$ & $M$ & $\overline{S D}$ & $M$ & $S D$ & $M$ & $S D$ & LVF & RVF \\
\hline $300 \mathrm{msec}$ & 836 & 160 & 837 & 155 & 867 & 182 & 849 & 152 & 31 & 12 \\
\hline $800 \mathrm{msec}$ & 782 & 162 & 750 & 172 & 761 & 181 & 760 & 169 & -21 & 10 \\
\hline
\end{tabular}

Note-For the affective priming index, positive scores reflect shorter reaction times in the congruent condition.

facilitated immediate recognition (Calvo \& Lang, 2005) when the pictures were presented parafoveally. A way to account for these discrepancies involves examining the role of prior identification of the stimuli as a prerequisite for affective processing. In the Calvo and Lang studies, the stimuli were presented several times across trials. Doing so provided the viewer with an opportunity to identify the stimulus objects in the previous trials. As Storbeck, Robinson, and McCourt (2006) have argued, it is possible that affective processing depends upon prior integration of perceptual stimulus features. If this is so, when the stimulus is presented parafoveally for the first time, processing of some perceptual features would be accomplished, but not affective processing. Only after prior foveal vision has allowed for processing of perceptual stimulus features will these later be accessible in parafoveal vision to the extent of enabling affective evaluation of the stimulus. To examine this account, we conducted Experiment 2.

\section{EXPERIMENT 2}

The new characteristic of Experiment 2 was a preview phase in which the participants were preexposed to the experimental stimuli once, with one picture at a time in foveal location, before their presentation in the parafoveal phase.

\section{Method}

Participants. Forty-eight undergraduates (36 females, 12 males) participated for course credit.

Stimuli,Apparatus, Procedure, and Design. Experiment 2 was identical to Experiment 1 except for the preview phase, which took place immediately before the parafoveal presentation phase (see Figure 1). In the preview phase, each of the 60 experimental pictures was randomly presented once for $1 \mathrm{sec}$. The participants were told that the photographs would be displayed quickly in the center of the screen and were asked just to pay attention to them-with no response required - since they would be presented later in an affective evaluation task. In the parafoveal presentation phase, each participant was presented with 16 practice trials plus 60 experimental trials.

\section{Results and Discussion}

A $2(\mathrm{SOA}) \times 2$ (valence of probe) $\times 2$ (prime-probe congruence) $\times 2$ (visual field of prime) ANOVA on RTs for correct responses yielded a significant SOA $\times$ congruence $\times$ visual field interaction $[F(1,46)=5.07, p<.05]$. To decompose the interaction, separate ANOVAs were conducted for each visual field. In the right visual field, there was no significant effect. In contrast, in the left field, there was an SOA $\times$ congruence interaction $[F(1,46)=$
$6.56, p<.025]$. Simple effect tests indicated that at the 300 -msec SOA, responses were faster for probes that were congruent with the prime than for those that were incongruent with the prime $[F(1,23)=7.85, p<.01]$. At an 800 -msec SOA, no differences emerged $(F<1)$. (See the mean scores in Table 2.)

To examine the contribution of foveal preview on parafoveal priming, the data from Experiments 1 and 2 were combined in a preview (no, Experiment 1 vs. yes, Experiment 2$) \times$ probe valence $\times$ prime-probe congruence $\times$ visual field ANOVA. The effects of SOA $[F(1,92)=7.64$, $p<.01]$ and a borderline SOA $\times$ congruence interaction $[F(1,92)=3.65, p=.058]$ were qualified by an SOA $\times$ congruence $\times$ visual field interaction $[F(1,92)=6.40$, $p<.025]$. As was the case for Experiment 2 separately, the combined three-way interaction revealed priming only for the left visual field at 300-msec SOA, where RTs were faster for congruent ( $825 \mathrm{msec})$ than for incongruent $(864 \mathrm{msec})$ probes $[F(1,46)=11.00, p<.01]$. Preview did not interact with any of the other factors (all $F$ s $<1$ ).

To explore the possibility that low-level properties in our pictorial stimuli might be involved in the observed priming effects, we assessed luminance (pleasant, $M=13.94$, $S D=2.82$; unpleasant, $M=13.29, S D=2.30)$, root-mean square contrast (Peli, 1990; pleasant, $M=3.38, S D=0.31$; unpleasant, $M=3.39, S D=0.17$ ), and red (pleasant, $M=$ $16.49, S D=3.32$; unpleasant, $M=15.23, S D=2.53$ ), green (pleasant, $M=13.05, S D=2.97$; unpleasant, $M=$ $12.73, S D=2.44$ ), and blue (pleasant, $M=11.46, S D=$ 3.02; unpleasant, $M=11.05, S D=2.57$ ) color saturation, by means of Adobe Photoshop (see Ochsner, 2000). There were no significant differences in any of these measures between the pleasant and the unpleasant stimuli $[$ all $F \mathrm{~S}<1$, except that for red saturation, $F(1,59)=2.72, p=.10]$.

Priming occurred when the prime stimuli appeared in the left visual field at a short $(300-\mathrm{msec})$ SOA. The lateralization effect is consistent with recent findings of Keil et al. (2005) showing activation in right cortical areas when emotional pictures were presented in the left visual field. A possible explanation involves right-hemisphere dominance for the processing of emotional pictures. This effect is, nevertheless, short-lived, which is in accordance with studies investigating foveal affective priming (Hermans et al., 1994; Hermans, Spruyt, \& Eelen, 2003). Note also that priming occurred when the stimuli were foveally previewed, before being presented parafoveally, in Experiment 2 . In contrast, the congruence effect did not reach 
Table 2

Reaction Times (in Milliseconds) for Correct Affective Evaluation Responses in Experiment 2, and Difference Scores (Incongruent - Congruent Conditions) for Each Visual Field (LVF, RVF) and Stimulus Onset Asynchrony (SOA)

\begin{tabular}{|c|c|c|c|c|c|c|c|c|c|c|}
\hline \multirow[b]{4}{*}{ SOA } & \multicolumn{8}{|c|}{ Prime-Probe Relatedness } & \multirow{3}{*}{\multicolumn{2}{|c|}{$\begin{array}{c}\text { Affective } \\
\text { Priming } \\
\text { (Differ. I - C }\end{array}$}} \\
\hline & \multicolumn{4}{|c|}{ Congruent (C) } & \multicolumn{4}{|c|}{ Incongruent (I) } & & \\
\hline & \multicolumn{2}{|c|}{ LVF } & \multicolumn{2}{|c|}{ RVF } & \multicolumn{2}{|c|}{ LVF } & \multicolumn{2}{|c|}{ RVF } & & \\
\hline & $M$ & $S D$ & $M$ & $S D$ & $M$ & $\overline{S D}$ & $M$ & $\overline{S D}$ & $\overline{\mathrm{LVF}}$ & RVF \\
\hline $300 \mathrm{msec}$ & 813 & 139 & 834 & 157 & 860 & 153 & 829 & 150 & $47^{*}$ & -5 \\
\hline $800 \mathrm{msec}$ & 774 & 163 & 755 & 160 & 763 & 160 & 767 & 151 & -11 & 12 \\
\hline
\end{tabular}

Note-For the affective priming index, positive scores reflect shorter reaction times in the congruent condition. ${ }^{*} p<.05$.

statistical significance in the absence of such a preview, in Experiment 1. This result is in line with proposals that object identification is a prerequisite for affective processing (Storbeck et al., 2006): Perceptual identification and affective assessment would not be parallel processes; the latter could not be performed until after the former had been accomplished. In our study, object identification was, presumably, performed during the foveal preview phase. The possibility that this occurred suggests that the object stimulus must be identified before the viewer can decide whether it is good or bad and that parafoveal processing of affect may involve recognition - rather than new perception and discrimination - of affect. Clearer support for this hypothesis, however, would have required an interaction involving preview, which was not the case when we combined the data from Experiments 1 and 2. This issue will be further addressed in Experiment 4.

Thus far, we have assumed that the priming effects were due to the processing of the emotional valence of the parafoveal pictures, which would facilitate (or interfere with) the evaluation of the congruent (or the incongruent) probes. It is, however, possible that nonaffective priming is involved in this effect, because of factors such as perceptual similarity and category relatedness between primes and probes (see Storbeck \& Robinson, 2004). Accordingly, a further issue is concerned with whether it is genuine affective content that is processed parafoveally or whether there is a possible confound with perceptual and semantic category content. We addressed this issue in Experiment 3.

\section{EXPERIMENT 3}

Two categories of visual scenes were used: people and animals. Instead of using primes depicting people, as occurred in the two previous experiments, in Experiment 3, only pictures of animals were included as primes for people probes. By doing so, not only were semantic category differences introduced between primes and probes, but perceptual differences also became greater. Thus, although the specific aim of Experiment 3 was to rule out a category priming account for the parafoveal affective priming effects, it was also relevant to rule out a perceptual similarity account. If truly affective content is extracted from emotional primes, priming will occur also when the prime and the probe belong to different semantic categories and have clearly different physical appearances.

\section{Method}

Participants. Fifty-six undergraduates (45 females, 11 males) participated for course credit.

Stimuli, Apparatus, Procedure, and Design. Thirty pictures portraying unpleasant scenes (20 about people, 10 about animals) and 30 pleasant scenes (20 about people, 10 about animals) were selected from IAPS (Center for the Study of Emotion and Attention, 1999). The IAPS numbers are indicated in the Appendix. A new sample of 7 pictures of animals ( 3 pleasant, 4 unpleasant) were added. The mean valence scores of the animal prime pictures were 3.55 (unpleasant) and 7.93 (pleasant) on a 9-point scale $[t(18)=$ $21.40, p<.0001]$. The respective rated arousal scores were 7.14 and $4.52[t(18)=9.88, p<.0001]$. The mean valence scores for the people probe pictures used in Experiment 2 were 2.43 (unpleasant) and 7.85 (pleasant) $[t(18)=32.16, p<.0001]$. The respective rated arousal scores were 6.65 and $4.94[t(18)=5.51, p<.0001]$.

Experiment 3 was identical to Experiment 2, except that pictures of animals were used as primes. The probes were concerned only with people scenes in order to make the affective evaluation data comparable with those in Experiments 1 and 2. In the preview phase, all of the pictures were randomly presented once (1 sec each). In the experimental phase, each participant was presented with different combinations of 10 unpleasant animals (primes) followed by 10 unpleasant people (probes), 10 unpleasant animals (primes) followed by 10 pleasant people (probes), 10 pleasant animals (primes) followed by 10 pleasant people (probes), and 10 pleasant animals (primes) followed by 10 unpleasant people (probes).

\section{Results and Discussion}

The $2(\mathrm{SOA}) \times 2$ (valence of probe) $\times 2$ (prime-probe congruence) $\times 2$ (visual field of prime) ANOVA on RTs in the affective evaluation task yielded significant effects of SOA $[F(1,54)=5.83, p<.025]$, with shorter RTs at $800-\mathrm{msec}(763 \mathrm{msec})$ than at $300-\mathrm{msec}(853 \mathrm{msec})$ SOA. There were also main effects of congruence $[F(1,54)=$ $4.05, p<.05]$ and an SOA $\times$ congruence interaction $[F(1,54)=4.43, p<.025]$. The mean scores are shown in Table 3. Simple effects tests indicated that at 300-msec $\mathrm{SOA}$, responses were faster for probes that were congruent with primes $(838 \mathrm{msec})$ than for those that were incongruent $(869 \mathrm{msec})[F(1,27)=6.06, p<.05]$. At $800-\mathrm{msec}$ SOA, no differences emerged as a function of congruence (763 msec for both). The priming effects at the $300-\mathrm{msec}$ SOA were further analyzed separately for each visual field. The 49-msec priming score in the left visual field was highly reliable $[F(1,27)=9.59, p<.01]$, whereas the 13-msec priming score in the right visual field did not reach statistical significance $(F<1)$.

To confirm the main finding across the first three experiments - that is, the priming effects for left visual field 
Table 3

Reaction Times (in Milliseconds) for Correct Affective Evaluation Responses

in Experiment 3, and Difference Scores (Incongruent - Congruent Conditions) for Each Visual Field (LVF, RVF) and Stimulus Onset Asynchrony (SOA)

\begin{tabular}{|c|c|c|c|c|c|c|c|c|c|c|}
\hline \multirow[b]{4}{*}{ SOA } & \multicolumn{8}{|c|}{ Prime-Probe Relatedness } & \multirow{3}{*}{\multicolumn{2}{|c|}{$\begin{array}{c}\text { Affective } \\
\text { Priming } \\
\text { (Differ. I - C }\end{array}$}} \\
\hline & \multicolumn{4}{|c|}{ Congruent (C) } & \multicolumn{4}{|c|}{ Incongruent (I) } & & \\
\hline & \multicolumn{2}{|c|}{ LVF } & \multicolumn{2}{|c|}{ RVF } & \multicolumn{2}{|c|}{ LVF } & \multicolumn{2}{|c|}{ RVF } & & \\
\hline & $M$ & $S D$ & $M$ & $\overline{S D}$ & $M$ & $S D$ & $M$ & $\overline{S D}$ & LVF & RVF \\
\hline $300 \mathrm{msec}$ & 828 & 169 & 848 & 162 & 877 & 169 & 861 & 159 & $49^{*}$ & 13 \\
\hline $800 \mathrm{msec}$ & 766 & 164 & 760 & 164 & 760 & 140 & 765 & 144 & -6 & 5 \\
\hline
\end{tabular}

Note-For the affective priming index, positive scores reflect shorter reaction times in the congruent condition. ${ }^{*} p<.05$.

primes at short SOA — and, given that the samples of participants were comparable, an overall ANOVA was performed involving experiment ( 1 vs. 2 vs. 3 ), SOA, probe valence, prime-probe congruence, and visual field. Response latencies were shorter at $800-\mathrm{msec}(764 \mathrm{msec})$ than at $300-\mathrm{msec}$ $(845 \mathrm{msec})$ SOA $[F(1,146)=13.21, p<.0001]$ and for congruent $(799 \mathrm{msec})$ than for incongruent $(810 \mathrm{msec})$ probes $[F(1,146)=5.71, p<.025]$. Furthermore, clear interactions of SOA $\times$ congruence $[F(1,146)=7.51, p<$ $.01]$ and SOA $\times$ congruence $\times$ visual field $[F(1,146)=$ $8.77, p<.01]$ emerged. Figure 2 shows this three-way interaction across experiments. Priming was significant in the left visual field at 300-msec SOA, where RTs were faster for congruent $(826 \mathrm{msec})$ than for incongruent $(868 \mathrm{msec})$ probes $[F(1,73)=20.01, p<.0001]$. The fact that experiment was not involved in any interaction (all $F_{\mathrm{s}}<1$, including the main effect) strengthens the consistent finding of fast and lateralized parafoveal affective priming.

The specific results of Experiment 3 indicate that there was generalization of priming across semantic categories (people and animals) and perceptual differences. This result implies that the underlying emotional content (beyond differences in category and physical appearance) was extracted from the prime and then affected processing of the probe. Some kind of nonperceptual and noncategory information must have been obtained from the parafoveal prime that then facilitated assessment of the probe emotional valence when the prime and probe shared the same valence. This interpretation is consistent with prior findings for foveal primes. Transfer of affective priming has been noted from primes to probes of a different nature, such as pictures (as primes) and words (as probes) (Banse, 2001; Carroll \& Young, 2005; Hermans, Spruyt, \& Eelen, 2003; Korpela, Klemettilä, \& Hietanen, 2002; Spruyt et al., 2002). More specifically, similar generalization across the people-animal categories was found by Avero and Calvo (2006) and Carroll and Young (2005; Experiment 2) when the prime scenes were presented at fixation. The present findings extend this priming effect from overtly attended to overtly unattended primes.

Thus far, we have assumed that the parafoveal stimuli were not directly looked at. Given the constraints on saccade latency (i.e., minimal latency for a saccade from the current fixation is about $150 \mathrm{msec}$; see Rayner, 1998), and that overt attention had to be allocated to the concurrent letter, it is very unlikely that the prime picture was foveally fixated. Nevertheless, this possibility has not been ruled out. Furthermore, we have noted the similarity in the

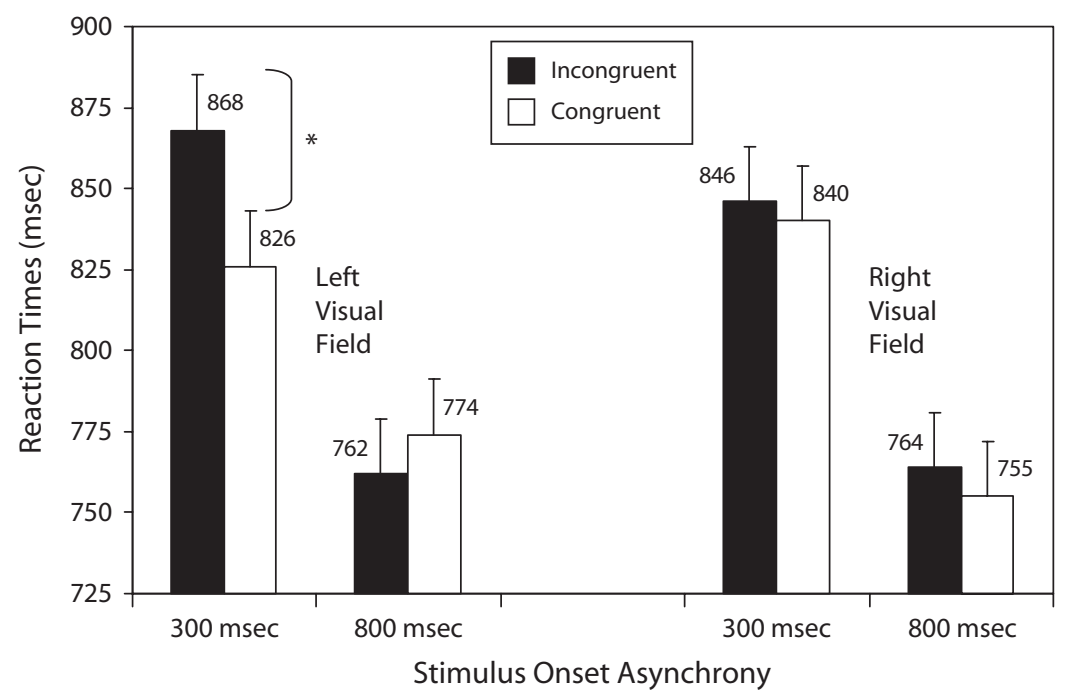

Figure 2. Mean response latencies (in milliseconds) as a function of affective primeprobe congruence, stimulus onset asynchrony, and visual field, across Experiments 1-3. " $p<.05$. 
time course of affective priming (i.e., fast and short-lived) between foveal and parafoveal presentation. This similarity may lead us to think that the priming effects that we have attributed to parafoveal processing were actually due to foveal analysis of the stimuli. We examined this alternative account in Experiment 4.

\section{EXPERIMENT 4}

This experiment was aimed, first, at testing (and ruling out) the possibility that the previous affective priming effects could have been due to overt attention to the parafoveal prime. Eye movements were recorded during the presentation of the parafoveal pictures. If priming involves truly parafoveal processing, then no eye fixations should occur on the primes. A second aim was concerned with the hypothesis that affective valence is really assessed parafoveally. In the previous experiments, the priming effects on the probes have been indirectly used to infer affective analysis of the primes. In the present experiment, we used a direct test of this assumption: Participants had to explicitly evaluate the affective valence of the parafoveal primes themselves, which were foveally masked if the viewers tried to look at the pictures. And, third, given that priming has emerged especially in the left visual field and after foveal preexposure, in Experiment 4, we examined the role of visual field and preexposure on eye movements and the evaluation of the parafoveal prime.

\section{Method}

Participants. Twenty-four undergraduates (20 females, 4 males) participated for course credit.

Stimuli, Apparatus, Procedure, and Design. The method was similar to that used in the previous experiments, with the following exceptions. First, 32 unpleasant and 32 pleasant visual scenes were employed (in addition to the 60 stimuli that were presented in the previous experiments, 2 more unpleasant and 2 more pleasant pictures were used from the IAPS; see the Appendix). Second, half of the participants underwent a preview phase in which the pictures were presented foveally ( $1 \mathrm{sec}$ each) prior to their presentation as primes in the experimental phase. The other half of the participants underwent a nonpreview phase in which 64 unrelated pictures were presented foveally. Third, only a 300-msec SOA was used, with the prime picture being displayed for $150 \mathrm{msec}$. Fourth, the participants assessed the affective valence of the prime rather than that of the probe. In fact, the probe no longer appeared, and it was replaced by a combination of meaningless colors. Fifth, the experimental conditions were combined in a mixed factorial design, with preview (yes vs. no) of the experimental pictures as a between-subjects factor ( 12 participants at each level) and prime valence (unpleasant vs. pleasant) and prime visual field (left vs. right) as within-subjects factors. Each picture was presented once, randomly. Half of the participants in each preview condition received half of the pictures of each valence level in the left visual field and the other half in the right visual field.

Finally, the most important difference involved the monitoring of eye movements. Stimuli were presented on a 21 -in. monitor with a $120-\mathrm{Hz}$ refresh rate, connected to a Pentium IV 3.2-GHz computer. Participants' eye movements were recorded with an EyeLink II tracker (SR Research Ltd., Mississauga, Ontario, Canada), connected to a Pentium IV 2.8-GHz host computer. The sampling rate of the eyetracker was $500 \mathrm{~Hz}$, and the spatial accuracy was better than $0.5^{\circ}$, with a $0.01^{\circ}$ resolution in pupil-tracking mode. The viewing distance was $60 \mathrm{~cm}$. The size of the pictures was $13.8^{\circ} \times 11^{\circ}$ $(14 \times 11 \mathrm{~cm})$, with the center of the fixation point at $2.5^{\circ}(2.5 \mathrm{~cm})$ of the inner edge of the prime pictures. An important technical innovation involved a gaze-contingent foveal black round mask (diameter $2.5^{\circ}$ ). This technique was used to prevent foveal viewing of the prime scenes. Participants were free to move their eyes during the presentation of the prime stimuli; however, wherever the viewer moved his/her gaze, foveal vision was blocked with the mask. Accordingly, whatever the viewer could see of the prime picture was due to parafoveal or peripheral vision. Figure 3 shows the sequence of events in a trial and a session.

Three eye movement measures were collected to determine whether there was orienting of attention to the prime stimuli: the probability that a saccade was initiated toward the prime, the probability that it landed on the prime before this stimulus disappeared, and the duration of this fixation. Two performance measures were employed to determine the extent to which the affective valence of the parafoveal prime was assessed: identification accuracy, or the probability of hits, and RTs.

\section{Results}

Probability of saccades and fixations on the parafoveal prime. Eye movements toward and on the parafoveal pictures were analyzed in 2 (preview) $\times 2$ (valence of prime) $\times 2$ (visual field of prime) ANOVAs. The duration of fixations on the prime picture area was also examined, when there was any. The mean probability of initiating a saccade from the central fixation point toward the prime stimulus was .135 (i.e., on $13.5 \%$ of trials), with no significant effect (all $p \mathrm{~s}>.15$ ). The mean probability that a saccade landed on the prime area was only .013 (i.e., $1.3 \%$ of trials). No effect reached statistical significance. There were only borderline effects of preview $[F(1,22)=3.49$, $p=.075]$ and visual field $[F(1,22)=3.44, p=.077]$, with a tendency to make more saccades following the nonpreview phase than following the preview phase (.023 vs. .003), and more fixations in the right than in the left visual field (.021 vs. .005). The mean end time of all saccades initiated from the central fixation point during the 150 -msec prime display - that is, the time taken to land on the prime stimulus area - was $171.5 \mathrm{msec}$, ranging between 149 and $203 \mathrm{msec}$ for the different experimental conditions. There were no statistically significant effects.

Hits and correct R'Ts. The probability that the participant correctly identified the valence of the prime, as well as the response latency on this task, was analyzed in 2 (preview) $\times 2$ (valence of prime) $\times 2$ (visual field of prime) ANOVAs. The mean scores for these dependent variables are shown in Table 4. The probability that hits (i.e., correct responses) were above the chance level (i.e., .50) was first examined by means of $t$ tests. For the nonpreview group, the difference between the empirical hit scores and the chance level was significant for all four experimental conditions [all $t \mathrm{~s}(11)>3.46, p<.01]$. For the preview group, the differences were also significant [all $t \mathrm{~s}(11)>11.40$, $p<.0001]$. The ANOVA yielded main effects of preview $[F(1,22)=19.25, p<.0001]$, prime valence $[F(1,22)=$ $16.65, p<.0001]$, and visual field $[F(1,22)=5.75, p<$ $.025]$. The hit rate was higher in the preview condition than in the nonpreview condition (.873 vs. 690) for pleasant as opposed to unpleasant scenes (.819 vs. .743), and in the left visual field than in the right visual field (.802 vs. .761). RTs for correct responses were also affected 


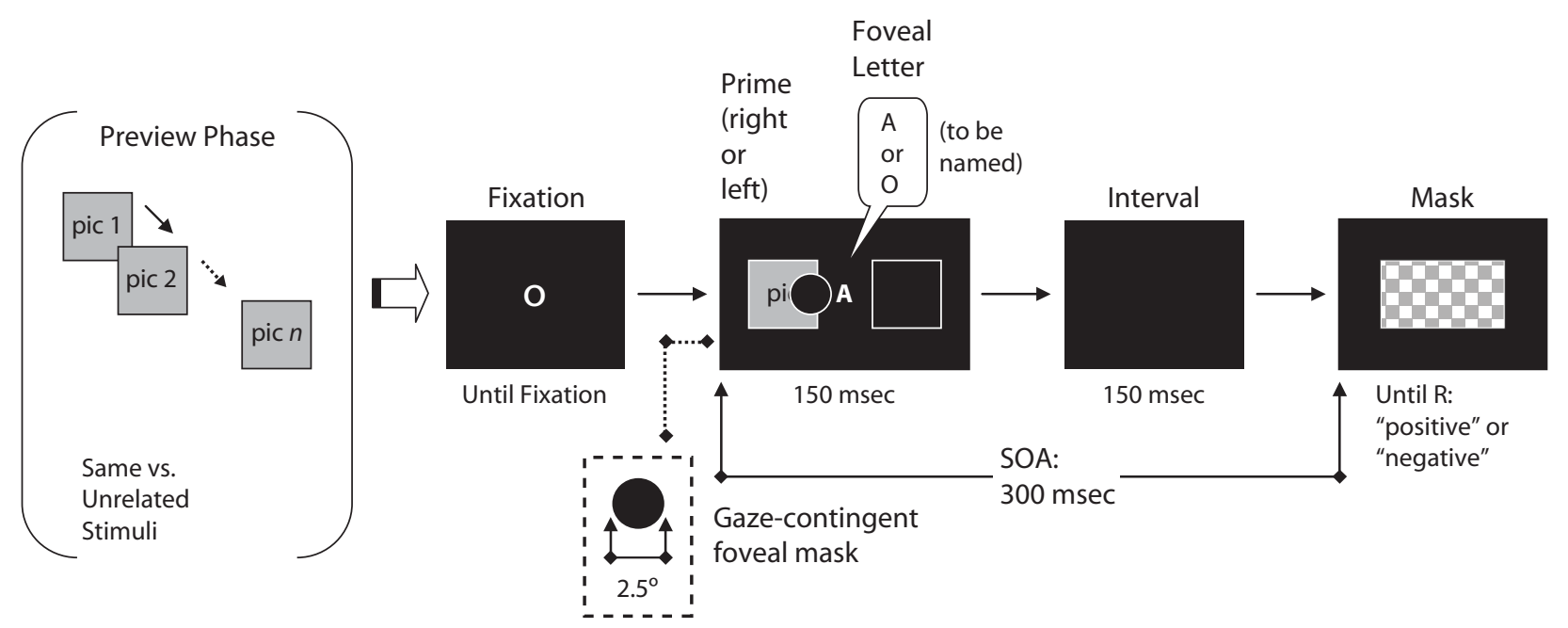

Figure 3. Sequence of events within a trial in Experiment 4.

by preview $[F(1,22)=7.50, p<.025]$, prime valence $[F(1,22)=11.25, p<.01]$, and visual field $[F(1,22)=$ $5.98, p<.025]$. Response latencies were shorter in the preview condition than in the nonpreview condition $(826$ vs. $975 \mathrm{msec}$ ), for pleasant than for unpleasant scenes ( 878 vs. $923 \mathrm{msec}$ ), and in the left visual field than in the right visual field ( 890 vs. $911 \mathrm{msec}$ ).

The results of Experiment 4 show two main findings. First, there were no fixations on the prime stimuli. Only on a few trials (and for no longer than $1 \mathrm{msec}$ ) did fixations land on the prime stimulus while this was still displayed (i.e., within the $150-\mathrm{msec}$ display period). This result indicates that the participants were not able to fixate the pictures, which were foveally masked, anyway. Second, response accuracy was above chance level in all conditions. Accordingly, the affective valence of the parafoveal prime scenes was assessed in the absence of fixations. The interpretation of the priming effects in the previous experiments as involving truly parafoveal processing of affective meaning is thus supported. Although the positive scenes were easier to identify than the negative scenes, as primes, this had no influence on affective priming. This conclusion is inferred from the lack of an interaction between valence and congruence, across experiments. Instead, there was a main congruence effect, or a congruence $\times \mathrm{SOA} \times$ visual field interaction. Such effects indicate that affective priming occurred similarly for both positive and negative pictures, as a function of their emotional valence, in spite of potential differences in other characteristics.

Furthermore, performance on the affective evaluation task was better both in response accuracy (higher) and latencies (shorter) for primes presented in the left visual field than for those in the right visual field, and it was better following foveal preview than following nonpreview of the scenes. This is also consistent with the previous results, in which affective priming occurred for primes presented to the left visual field and after foveal preexposure. Note that in Experiment 4, the left visual field advantage and the preview advantage in the identification of the primes occurred even though the tendency for saccades and fixations was in the direction opposite to that of performance in the evaluation task. In general, putting the findings of Experiment 4 and those of Experiments 1-3 together, one can conclude that the affective valence of emotional scenes can be extracted in truly parafoveal vision, without foveal fixations on the stimuli, and that this applies especially to stimuli that are presented in the left visual field and after foveal preview.

\section{GENERAL DISCUSSION}

We have investigated whether emotional information can be obtained from visual scenes when they are presented in extrafoveal locations of the visual field with no

Table 4

Probability of Correct Affective Evaluation Responses and Reaction Times (RTs, in Milliseconds) As a Function of Preexposure, Prime Valence, and Visual Field (LVF, RVF) in Experiment 4

\begin{tabular}{|c|c|c|c|c|c|c|c|c|c|c|c|c|c|c|c|c|}
\hline \multirow[b]{4}{*}{ Preexposure } & \multicolumn{8}{|c|}{ Probability of Correct Responses } & \multicolumn{8}{|c|}{ RTs } \\
\hline & \multicolumn{4}{|c|}{ Unpleasant Scenes } & \multicolumn{4}{|c|}{ Pleasant Scenes } & \multicolumn{4}{|c|}{ Unpleasant Scenes } & \multicolumn{4}{|c|}{ Pleasant Scenes } \\
\hline & \multicolumn{2}{|c|}{ LVF } & \multicolumn{2}{|c|}{ RVF } & \multicolumn{2}{|c|}{ LVF } & \multicolumn{2}{|c|}{ RVF } & \multicolumn{2}{|c|}{ LVF } & \multicolumn{2}{|c|}{ RVF } & \multicolumn{2}{|c|}{ LVF } & \multicolumn{2}{|c|}{ RVF } \\
\hline & $M$ & $S D$ & $M$ & $S D$ & $M$ & $S D$ & $M$ & $S D$ & $M$ & $S D$ & $M$ & $S D$ & $M$ & $S D$ & $M$ & $S D$ \\
\hline Nonpreview & .641 & .128 & .651 & .150 & .749 & .138 & .719 & .202 & 973 & 144 & 1,015 & 161 & 956 & 136 & 956 & 160 \\
\hline Preview & .880 & .068 & .802 & .192 & .937 & .065 & .871 & .094 & 850 & 132 & 856 & 135 & 783 & 110 & 815 & 141 \\
\hline
\end{tabular}

Note-All probability scores in the nonpreview condition and in the preview condition differed from the chance level $(.50)$ at $p<.01$ and $p<.001$, respectively. 
eye fixations on the stimulus or, more generally, whether emotional content can be "seen" without being foveally looked at. The issue was addressed by presenting a parafoveal prime picture $2.5^{\circ}$ of visual angle away from a central fixation letter to be named, in addition to gaze-contingent foveal masking of the picture. Eye-tracking measures confirmed that there were no fixations on the parafoveal stimuli during the prime display. Affective priming in such conditions - that is, shorter response latencies for probes when the probe was congruent in affective valence with a prime than when it was incongruent-allows us to infer that the prime emotional significance was assessed and that positive and negative stimulus affect were discriminated. This conclusion is further strengthened by the fact that there was stimulus generalization, since priming occurred even when primes and probes belonged to different semantic categories and there were considerable perceptual differences. It was when the prime and the probe shared the same valence that affective priming occurred.

In addition to demonstrating that affective content is assessed parafoveally, our findings are particularly relevant in examining the role of covert attention in emotional processing — in the absence of overt attention - with regard to two groups of questions: when and how affective content is activated, and where in the visual field (and the brain) the process is especially likely to take place.

\section{Mental Resources for Parafoveal Processing of Affective Content: When and How?}

The first issue is concerned with time course and attentional involvement in the processing of affective stimulus content. Affective priming was observed $300 \mathrm{msec}$ after the onset of the prime picture, but not later $(800-\mathrm{msec}$ SOA). This result suggests that parafoveal affective priming is fast activated but is short lived. This is in agreement with most prior research on foveal affective priming showing effects at short SOAs (300 msec or less) that disappear later (1,000-msec SOAs; Hermans et al., 1994; Hermans, De Houwer, \& Eelen, 2001; Hermans, Spruyt, \& Eelen, 2003), although priming has also been found sometimes at later stages (with 700- to 2,000-msec SOAs; Carroll \& Young, 2005). The speed with which a cognitive process is performed is one of the typical criteria of automaticity (see Moors \& De Houwer, 2006). Accordingly, from the early effects in parafoveal affective priming, we can infer that this is automatic in the sense of being quickly performed. If it were strategic, then priming would remain or even increase over time, which was not the case.

Nevertheless, Moors and De Houwer (2006) have argued that an all-or-nothing view of automaticity is incorrect, in that automaticity involves several features, and most cognitive processes possess both automatic and nonautomatic characteristics. In addition to processing speed, three major characteristics of automaticity have been identified - that is, (un)awareness, (un)intentionality, and efficiency (Moors \& De Houwer, 2006). Our findings are also relevant to these criteria. Regarding awareness and intentionality, conscious identification of the emotional valence of the parafoveal - and foveally masked - prime was above the chance level. This result implies that the affective content of parafoveal scenes is accessible to conscious analysis, at least under conditions involving intentional evaluation, as was the case in the present study. This implication, however, does not exclude the possibility that affective priming can occur outside awareness for foveal pictures (Banse, 2001; Hermans, Spruyt, De Houwer, \& Eelen, 2003). Regarding efficiency, parallel processing is an important aspect. The parafoveal prime picture was presented while attentional resources were engaged in identifying a foveal letter. Given that the picture and the letter were exposed for only $150 \mathrm{msec}$, as well as the lack of eye fixations on the prime pictures, it is very unlikely that serial processing of the picture occurred following the letter identification. This finding implies that there must have been parallel processing of the parafoveal picture by means of covert attention.

The fact that affective processing can occur under conditions of reduced attentional deployment should not, however, lead us to think that affective processing is insensitive to attentional limitations. Recently, Calvo and Nummenmaa (2007) examined the extent to which parafoveal encoding of emotional scenes is resource limited versus data limited. Affective evaluation of parafoveally presented, foveally masked scenes was compared under single-task conditions (only the prime pictures were presented) or dual-task conditions (picture evaluation + letter naming, as was the case in the present study), across three or four repeated blocks. Two types of data obtained by Calvo and Nummenmaa favored the resource-limited account by showing that valence encoding was impaired by attentional load. First, accuracy in the identification of the prime valence was affected interactively by block and task, so that performance was impaired in the dualtask condition in the first block. This result reveals that when identification is more difficult (i.e., without any prior exposure to the stimuli), resource consumption by attentional load limits the encoding of valence. Second, there was a main effect of task condition on RTs in affective evaluation of the prime scenes, so that response latencies were longer in the dual- than in the single-task condition. This effect indicates that affective encoding of the overtly unattended prime valence relies on the availability of capacity-limited covert attentional resources (see also Smith-Erthal et al., 2005).

A final related aspect to be considered is the role of preexposure. In our experiments, affective priming emerged when the parafoveal pictures were preexposed foveally (Experiments 2 and 3), but the effect did not reach statistical significance in the absence of a foveal preview of the stimuli (Experiment 1). Furthermore, accuracy in affective evaluation of the parafoveal primes was higher and RTs were shorter following a foveal preview phase (Experiment 4). In a systematic approach to this issue, Calvo and Nummenmaa (2007) noted a gradual increase in affective priming across blocks both when the parafoveal primes were preexposed foveally and when they were preexposed only parafoveally. This increase suggests that preexposure strengthens the capability of the visual system to rapidly detect affectively relevant features, and it is consistent with recent neuroscience findings show- 
ing adaptation and/or plasticity in emotional perception. Storalova et al. (2006) demonstrated modulation of the early $\mathrm{C} 1$ visual event-related component for threat-related versus neutral pictures, which increased with continuing acquisition of affective meaning. These authors interpret the findings as indicating a short-term reorganization in the visual cortex, enabling sensory amplification of visual features that are relevant to emotional information.

\section{Visual and Brain Hardware for Parafoveal Processing of Affective Content: Where?}

The second major issue is concerned with lateralization. In our study, affective priming generally occurred when the primes appeared to the left of fixation. Also, identification of affective valence of the parafoveal stimulus was better (more accurate and faster) in the left visual field, in the absence of fixations. This result can be interpreted within the context of brain hemisphere specializations and would indicate that there is right-hemisphere dominance for the processing of emotional content. This idea is consistent with right-hemisphere models of emotion perception (Adolphs, Damasio, Tranel, \& Damasio, 1996; Borod et al., 1998; Heller, Nitschke, \& Miller, 1998). In contrast, our findings do not support the valence specificity hypothesis, according to which there should be a right-hemisphere advantage for the perception of negative emotions and a left-hemisphere advantage for the processing of positive emotions. Furthermore, some studies have shown that the valence specificity hypothesis may depend upon the gender of the participant, with only women showing the valence-specific laterality effects (Rodway et al., 2003; van Strien \& van Beek, 2000). Burton and Levy (1989) found that women, but not men, perceived faces with negative emotions the fastest when they were presented in the left visual field, and they perceived faces with positive emotions the fastest when they were presented in the right visual field. Our results indicate that affective congruence produced priming in the left visual field for both positively and negatively valenced pictures, even though the sample of participants was composed mainly (79\%) of females.

In contrast with these findings, a meta-analysis combining results from 106 brain-imaging studies on emotion (Murphy et al., 2003) failed to support a special role of the right hemisphere in emotion perception. Nevertheless, note that in addition to including a wide range of stimulus modalities in the meta-analysis (visual, auditory, olfactory, tactile, and taste), there was considerable variety in the stimulus format and content within the visual modality (scenes, faces, films, ideograms, sentences, words, and imagery). The argument has already been made that scenes depicting emotional face expressions in an action context might have a different status in terms of emotional intensity and informativeness (see the introduction). Support for the right-hemisphere dominance hypothesis comes from two types of studies that have used emotional visual scenes as stimuli. Evidence is provided, first, by studies using localization measures, such as fMRI, MEG (magnetoencephalography), and PET, to assess brain activity during the presentation of pictures in central vision. With
fMRI, Lang et al. (1998) found more activation for both pleasant and unpleasant scenes than for neutral scenes in the right-posterior region of the occipital cortex. Also, Bradley et al. (2003) reported more fMRI activity for emotional than for neutral scenes at both right and left sites of the posterior visual cortex, although the difference was greatest in the right side, particularly for highly arousing unpleasant scenes. Using MEG, Moratti, Keil, and Storalova (2004) observed greater activity in fronto-parietal cortical networks elicited by high-arousing (both unpleasant and pleasant) scenes than in those elicited by low-arousing (neutral) scenes, with a right-hemispheric dominance. With PET, Lane, Chua, and Dolan (1999) noted more activation in the extrastriate visual cortex and right-anterior temporal cortex for high-arousal unpleasant scenes. A second source of evidence comes from data obtained with the divided visual field technique. Keil et al. (2005) found right occipitotemporal and parietal activation when unpleasant scenes were presented in the left visual field $\left(1.3^{\circ}\right.$ away from the central fixation point). The present study has extended these findings to more eccentric, truly parafoveal locations $\left(2.5^{\circ}\right)$ and to both pleasant and unpleasant stimuli.

The hypothesis that the right hemisphere has a special role in the processing of emotional faces has received further support from a different methodological approach. Burton et al. (2003) compared patients who had undergone right (RTL) or left (LTL) temporal lobectomy (including removal of the amygdala and the hippocampus), in a task involving either perception and priming of affective facial expressions or processing of neutral features of the faces. These authors found that the performance of the LTL patients (and also of a normative sample of participants with both hemispheres intact; see Burton et al., 2005) improved when the task had an affective (vs. neutral) component, whereas the RTL patients did not show this benefit.

From the observed left visual field advantage, we have concluded that there is a right-hemisphere advantage in emotional processing. One could, however, argue that this advantage might occur for any pictorial stimulus, independently of emotional content. Data from a recent study by Calvo and Nummenmaa (2007) are relevant to this issue. These authors compared affective and semantic processing by varying the task relevance of the affective or semantic attributes of the same stimuli. Essentially, pleasant or unpleasant scenes portraying people or animals were presented as primes and probes, and participants had to make either an affective evaluation (pleasant or unpleasant) or a semantic categorization (people or animal) of the probe. Results revealed both affective and semantic parafoveal priming. Nevertheless, regarding lateralization, valence encoding and category encoding were affected by visual field in a different fashion. There was semantic priming only when primes were presented in the right visual field, whereas affective priming more generally appeared in the left field. These findings further support the hypothesis of right-hemisphere specialization for encoding the valence of emotional pictures.

\section{Conclusions}

The following conclusions can be drawn. First, the affective meaning of emotional visual scenes can be ana- 
lyzed by covert attention mechanisms, without overt attention to the stimuli - that is, when these are not foveally fixated or when they are foveally masked. Second, the affective significance of parafoveal stimuli is assessed early, since affective priming appeared at 300-msec SOA. Third, priming occurs as a function of affective prime-probe congruence, regardless of differences in physical appearance and semantic category. Fourth, the encoding of affective content of parafoveal scenes takes place when the parafoveal stimulus has been preexposed foveally. And, finally, right-hemispheric neural structures may be particularly involved in the processing of affective meaning, since priming emerged when the stimuli were presented in the left visual field. In general, these findings are consistent with a functional, adaptive view of the cognitive system and the brain (see Lang, Bradley, \& Cuthbert, 1997; Vuilleumier, 2005) as being especially sensitive to emotional events. Early affective evaluation and discrimination, which can also occur in parallel to other cognitive activity and under reduced attention, serve to maximize detection of stimuli that are important for well-being and to enhance readiness for defensive and appetitive behavior.

\section{AUTHOR NOTE}

This research was supported by Grant SEJ2004-420/PSIC from the Spanish Ministry of Education and Science. We acknowledge the comments of Jukka Hyönä, Peter Lang, and Margaret Gillon Dowens on an earlier version of this article. We thank Monica Aguilar Oliva for her assistance in data collection. Correspondence concerning this article should be sent to M. G. Calvo, Department of Cognitive Psychology, Universidad de La Laguna, 38205 Tenerife, Spain (e-mail: mgcalvo@ull.es).

Note-This article was accepted by the previous editorial team, when John Jonides was Editor.

\section{REFERENCES}

Adolphs, R., Damasio, H., Tranel, D., \& Damasio, A. R. (1996). Cortical systems for the recognition of emotion in facial expression. Journal of Neuroscience, 16, 7678-7687.

Avero, P., \& Calvo, M. G. (2006). Affective priming with pictures of emotional scenes: The role of perceptual similarity and category relatedness. Spanish Journal of Psychology, 9, 10-18.

BANSE, R. (2001). Affective priming with liked and disliked persons: Prime visibility determines congruency and incongruency effects. Cognition \& Emotion, 15, 501-520.

BARGH, J. A. (1997). The automaticity of everyday life. In R. S. Wyer, Jr. (Ed.), The automaticity of everyday life (Advances in Social Cognition, Vol. 10, pp. 1-61). Mahwah, NJ: Erlbaum.

Borod, J. C., Cicero, B. A., Obler, L. K., Welkowitz, J., Erhan, H. M., SANTSCHI, C., ET AL. (1998). Right hemisphere emotional perception: Evidence across multiple channels. Neuropsychology, 12, 446-458.

Borod, J. C., Zgaljardic, D., Tabert, M. H., \& Koff, E. (2001). Asymmetries of emotional perception and expression in normal adults. In F. Boller \& J. Grafman (Series Eds.) and L. Squire \& G. Gainotti (Vol. Eds.), Handbook of neuropsychology: Vol. 3. Section 5. Emotional behavior and its disorders (pp. 181-206). Amsterdam: Elsevier.

Bradley, M. M., Sabatinelli, D., Lang, P. J., Fitzsimmons, J. R., KING, W., \& DesaI, P. (2003). Activation of the visual cortex in motivated attention. Behavioral Neuroscience, 117, 369-380.

Burton, L. A., \& LeVy, J. (1989). Sex differences in lateralized processing of facial emotion. Brain \& Cognition, 11, 210-228.

Burton, L. A., Rabin, L., Wyatt, G., Frolich, J., BernsteinVArdy, S., \& Dimitri, D. (2005). Priming effects for affective vs. neutral faces. Brain \& Cognition, 59, 322-329.
Burton, L. A., Wyatt, G., Rabin, L., Frolich, J., BernsteinVARdY, S., Dimitri, D., \& LABAR, D. (2003). Perception and priming of affective faces in temporal lobectomy patients. Journal of Clinical \& Experimental Neuropsychology, 25, 348-360.

Calvo, M. G., \& Esteves, F. (2005). Detection of emotional faces: Low perceptual threshold and wide attentional span. Visual Cognition, 12, 13-27.

Calvo, M. G., \& Lang, P. J. (2004). Gaze patterns when looking at emotional pictures: Motivationally biased attention. Motivation \& Emotion, 28, 221-243.

Calvo, M. G., \& Lang, P. J. (2005). Parafoveal semantic processing of emotional visual scenes. Journal of Experimental Psychology: Human Perception \& Performance, 31, 502-519.

Calvo, M. G., \& Nummenmaa, L. (2007). Processing of unattended emotional visual scenes. Journal of Experimental Psychology: General, 136, 347-369.

Carroll, N. C., \& Young, A.W. (2005). Priming of emotion recognition. Quarterly Journal of Experimental Psychology, 58A, 1173-1197.

CEnTER For the Study of EMotion ANd AtTENTION [CSEA-NIMH] (1999). The International Affective Picture System: Digitized photographs. Gainesville: University of Florida Center for Research in Psychophysiology.

Corbetta, M. (1998). Frontoparietal cortical networks for directing attention and the eye to visual locations: Identical, independence, or overlapping neural systems? Proceedings of the National Academy of Sciences, 95, 831-838.

Dimberg, U., Thunberg, M., \& Elmehed, K. (2000). Unconscious facial reactions to emotional facial expressions. Psychological Science, 11, 86-89.

Eimer, M., Holmes, A., \& McGlone, F. P. (2003). The role of spatial attention in the processing of facial expression: An ERP study of rapid brain responses to six basic emotions. Cognitive, Affective, \& Behavioral Neuroscience, 3, 97-110.

Findlay, J. M., \& Gilchrist, I. (2003). Active vision: The psychology of looking and seeing. Oxford: Oxford University Press.

Heller, W., NitschKe, J. N., \& Miller, G. A. (1998). Lateralization in emotion and emotional disorders. Current Directions in Psychological Science, 7, 26-32.

Hermans, D., De Houwer, J., \& Eelen, P. (1994). The affective priming effect: Automatic activation of evaluative information in memory. Cognition \& Emotion, 8, 515-533.

Hermans, D., De Houwer, J., \& Eelen, P. (2001). A time course analysis of the affective priming effect. Cognition \& Emotion, 15, 143-165.

Hermans, D., Spruyt, A., De Houwer, J., \& Eelen, P. (2003). Affective priming with subliminally presented pictures. Canadian Journal of Experimental Psychology, 57, 97-114.

Hermans, D., Spruyt, A., \& Eelen, P. (2003). Automatic affective priming of recently acquired stimulus valence: Priming at SOA 300 but not at SOA 1000. Cognition \& Emotion, 17, 83-99.

Hietanen, J. K., \& Korpela, K. M. (2004). Do both negative and positive environmental scenes elicit rapid affective processing? Environment \& Behavior, 36, 558-577.

Ignashchenkova, A., Dicke, P. W., HaArmeier, T., \& Their, P. (2004). Neuron-specific contribution of the superior colliculus to overt and covert shifts of attention. Nature Neuroscience, 7, 56-64.

Keil, A., Moratti, S., Sabatinelli, D., Bradley, M. M., \& Lang, P. J. (2005). Additive effects of emotional content and spatial selective attention on electrocortical facilitation. Cerebral Cortex, 15, 1187-1197.

Keil, A., Müller, M. M., Gruber, T., Wienbruch, C., Storalova, M., \& Elbert, T. (2001). Effects of emotional arousal in the cerebral hemispheres: A study of oscillatory brain activity and eventrelated potentials. Clinical Neurophysiology, 112, 2057-2068.

Klauer, K. C., \& Musch, J. (2003). Affective priming. Findings and theories. In J. Musch \& K. C. Klauer (Eds.), The psychology of evaluation: Affective processes in cognition and emotion (pp. 7-49). Mahwah, NJ: Erlbaum.

Korpela, K. M., Klemettilä, T., \& Hietanen, J. K. (2002). Evidence for rapid affective evaluation of environmental scenes. Environment \& Behavior, 34, 634-650.

Lane, R. D., Chua, P., \& Dolan, R. J. (1999). Common effects of emotional valence, arousal and attention on neural activation during visual processing of pictures. Neuropsychologia, 37, 989-997. 
Lang, P. J., Bradley, M. M., \& Cuthbert, B. N. (1997). Motivated attention: Affect, activation and action. In P. J. Lang, R. F. Simmons, \& M. T. Balaban (Eds.), Attention and orienting: Sensory and motivational processes (pp. 97-135). Mahwah, NJ: Erlbaum.

Lang, P. J., Bradley, M. M., Fitzsimmons, J. R., Cuthbert, B. N., Scott, J. D., Moulder, B., \& NAngia, V. (1998). Emotional arousal and activation of the visual cortex: An fMRI analysis. Psychophysiology, 35, 199-210.

Moors, A., \& De Houwer, J. (2006). Automaticity: A conceptual and theoretical analysis. Psychological Bulletin, 132, 297-326.

Moratti, S., KeIl, A., \& Storalova, M. (2004). Motivated attention in emotional picture processing is reflected by activity modulation in cortical attention networks. NeuroImage, 21, 954-964.

Murphy, F. C., Nimmo-Smith, I., \& Lawrence, A. D. (2003). Functional neuroanatomy of emotions: A meta-analysis. Cognitive, Affective, \& Behavioral Neuroscience, 3, 207-233.

NummenmaA, L., HyönÄ, J., \& CALVo, M. G. (2006). Eye-movement assessment of selective attentional capture by emotional pictures. Emotion, 6, 257-268.

OCHSNER, K. N. (2000). Are affective events richly recollected or simply familiar? The experience and process of recognizing feelings past. Journal of Experimental Psychology: General, 129, 242-261.

Öhman, A., \& SoARES, J. J. (1998). Emotional conditioning to masked stimuli: Expectancies for aversive outcomes following non-recognized fear-relevant stimuli. Journal of Experimental Psychology: General, 127, 69-82.

Peli, E. (1990). Contrast in complex images. Journal of the Optical Society of America, 7, 2032-2040.

Pessoa, L., McKenna, M., Gutierrez, E., \& Ungerleider, L. G. (2002). Neural processing of emotional faces requires attention. Proceedings of the National Academy of Sciences, 99, 11458-11463.

Pizzagalli, D., Regard, M., \& Lehmann, D. (1999). Rapid emotional face processing in the human right and left brain hemispheres: An ERP study. NeuroReport, 10, 2691-2698.

Posner, M. I., \& Petersen, S. E. (1990). The attention system of the human brain. Annual Review of Neuroscience, 13, 25-41.

Pourtois, G., Thut, G., Grave de Peralta, R., Michel, C., \& VuilLEUMIER, P. (2005). Two electrophysiological stages of spatial orienting towards fearful faces: Early temporo-parietal activation preceding gain control in extrastriate visual cortex. NeuroImage, 26, 149-163.

RAYNER, K. (1998). Eye movements in reading and information processing: 20 years of research. Psychological Bulletin, 124, 372-422.
Rodway, P., Wright, L., \& Hardie, S. (2003). The valence-specific laterality effect in free-viewing conditions: The influence of sex, handedness, and response bias. Brain \& Cognition, 53, 452-463.

Schneider, W., Eschman, A., \& Zuccolotto, A. (2002). E-Prime user's guide. Pittsburgh, PA: Psychology Software Tools.

Smith-Erthal, F., de Oliveira, L., Mocaiber, I., García-Pereira, M., Machado-Pinhneiro, W., Volchan, E., \& Pessoa, L. (2005). Loaddependent modulation of affective picture processing. Cognitive, Affective, \& Behavioral Neuroscience, 5, 388-395.

Spruyt, A., Hermans, D., De Houwer, J., \& Eelen, P. (2002). On the nature of the affective priming effect: Affective priming of naming responses. Social Cognition, 20, 227-256.

Storalova, M., KeIl, A., \& Moratti, S. (2006). Modulation of C1 visual event-related component by conditioned stimuli: Evidence for sensory plasticity in early affective perception. Cerebral Cortex, 16, 876-887.

Storbeck, J., \& Robinson, M. D. (2004). Preferences and inferences in encoding of visual objects: A systematic comparison of semantic and affective priming. Personality \& Social Psychology Bulletin, 30, 81-93.

Storbeck, J., Robinson, M. D., \& McCourt, M. E. (2006). Semantic processing precedes affect retrieval: The neurological case for cognitive primacy in visual processing. Review of General Psychology, 10, 41-55.

van Strien, J. W., \& van Beek, S. (2000). Ratings of emotion in laterally presented faces: Sex and handedness effects. Brain \& Cognition, 44, 645-652.

Vuilleumier, P. (2005). How brains beware: Neural mechanisms of emotional attention. Trends in Cognitive Sciences, 9, 585-594.

Vuilleumier, P., Armony, J. L., Driver, J., \& Dolan, R. J. (2001). Effects of attention and emotion on face processing in the human brain: An event-related fMRI study. Neuron, 30, 829-841.

Wandell, B. A. (1995). Foundations of vision. Sunderland, MA: Sinauer.

Wu, S. C., \& Remington, R. W. (2003). Characteristics of covert and overt visual orienting: Evidence from attentional and oculomotor capture. Journal of Experimental Psychology: Human Perception \& Performance, 29, 1050-1067.

ZaJonc, R. (2000). Feeling and thinking: Closing the debate over the independence of affect. In J. P. Forgas (Ed.), Feeling and thinking: The role of affect in social cognition (pp. 31-58). New York: Cambridge University Press.

\section{APPENDIX \\ IAPS Number of Pictures Used as Pleasant and Unpleasant Primes and Probes in Experiments 1-3 \\ Pleasant (people): \\ $2000^{*}, 2040,2057,2070,2092^{*}, 2160^{*}, 2165,2311,2332^{*}, 2340^{*}, 2341,2352,2360,2395,2540^{*}, 2550$, $4574,4599,4624^{*}, 4641,4653,4660^{*}, 4680^{*}, 4687,4694^{*}, 4695^{\#}, 4700,7325,8205^{\#}, 8461,8490,8499$.}

\section{Pleasant (animals):}

1440, 1441, 1460, 1463, 1710, 1750, 1920; non-IAPS: pa1, pa9, pa10.

\section{Unpleasant (people):}

$2120,2683^{*}, 2691,2703,2799^{*}, 2800^{*}, 2900,3022^{*}, 3030,3180,3181^{*}, 3350,3530,3550,6243^{\#}, 6250$, 6313, 6315", 6510*, 6550, 6560, 8231, 9040*, 9230, 9250, 9254*, 9410, 9421* , 9429, 9440, 9594, 9921*.

\section{Unpleasant (animals):}

1050, 1205, 1300, 1525, 1726, 1930; non-IAPS: na1, na2, na9, na10.

*Not included in Experiment 3. \#Included in Experiment 4. 